\title{
A crise e a gripe suína
}

Luciano Nakabashi*

RESUMO - Assim como a gripe suína, a crise causou um certo pânico inicial, mas foi bem mais amena no Brasil em relação aos países do norte, e está se dissipando rapidamente com o início da primavera. A expectativa é que a economia brasileira já apresente uma boa recuperação a partir de 2010. Já no caso da gripe, a incerteza para o próximo ano é maior e depende, entre outras coisas, dos avanços da ciência. No entanto, apesar da recuperação, cabe aos gestores de política econômica uma atenção maior em relação à evolução da estrutura da pauta de exportações.

Palavras-chave: Crise. Exportações. Economia brasileira.

\section{INTRODUÇÃO}

Apesar das discordâncias e erros dos economistas e demais analistas econômicos, pode-se dizer que as análises e previsões realizadas por esses profissionais, pelo menos no caso da economia brasileira, foram satisfatórias.

Em um momento atípico de recessão mais profunda que se espalha pelo mundo inteiro, como no caso atual, a incerteza é muito grande devido a diversos fatores e, principalmente, pela instabilidade no humor dos consumidores e investidores em relação ao futuro próximo da economia. Uma crise nas proporções atuais afeta vários segmentos de diversas nações e uma piora nas expectativas dos agentes pode levar a uma relevante queda na demanda e aprofundamento dos problemas já existentes, além do efeito de contágio para outros segmentos, setores e países. Por isso, é natural que erros de previsão sejam cometidos.

Devidos a essa grande incerteza, os economistas foram surpreendidos com o desempenho da economia brasileira no último trimestre de 2009. No entanto, com alguns ajustes, as previsões se mostraram um tanto quanto próximas da evolução dos impactos da crise na economia brasileira e sobre o seu desempenho em 2009.

\footnotetext{
* Doutor em economia, professor do Departamento de Economia da UFPR e coordenador do Boletim de Economia \& Tecnologia. Endereço eletrônico: luciano.nakabashi@ufpr.br.
} 


\subsection{OS CANAIS DO CONTÁGIO DA CRISE NO BRASIL}

Os estudos realizados para mensurar os impactos da crise financeira internacional na economia brasileira, até o final de 2008 , se mostraram muito otimistas. Havia um certo consenso de que nossa economia apresentava fundamentos sólidos, o sistema bancário não tinha nenhum envolvimento direto ou indireto com o sistema imobiliário norte-americano e que os saldos positivos das contas externas haviam nos fornecido um "seguro" contra repentinas fugas de capitais. Daí, a impressão de que a economia brasileira continuaria a crescer apenas com pequenos arranhões ou que toda crise externa seria apenas como uma "marolinha" para o Brasil.

Todos esses fatores apontados acima que indicavam para um reduzido impacto da crise se mostraram corretos, mas ocorreu certa subestimação do potencial de outros canais de contágio da crise, principalmente das exportações e das expectativas.

No gráfico 1, podemos visualizar a grande redução das exportações brasileiras a partir de setembro de 2008. Cabe ressaltar que os principais efeitos da crise sobre o PIB brasileiro foram sentidos justamente a partir de setembro de 2008 e o comportamento próximo dessas duas variáveis não é apenas uma coincidência.

\section{GRÁFICO 1 - EVOLUÇÃO DAS EXPORTAÇÕES BRASILEIRA ENTRE 1/1994 E 9/2009}

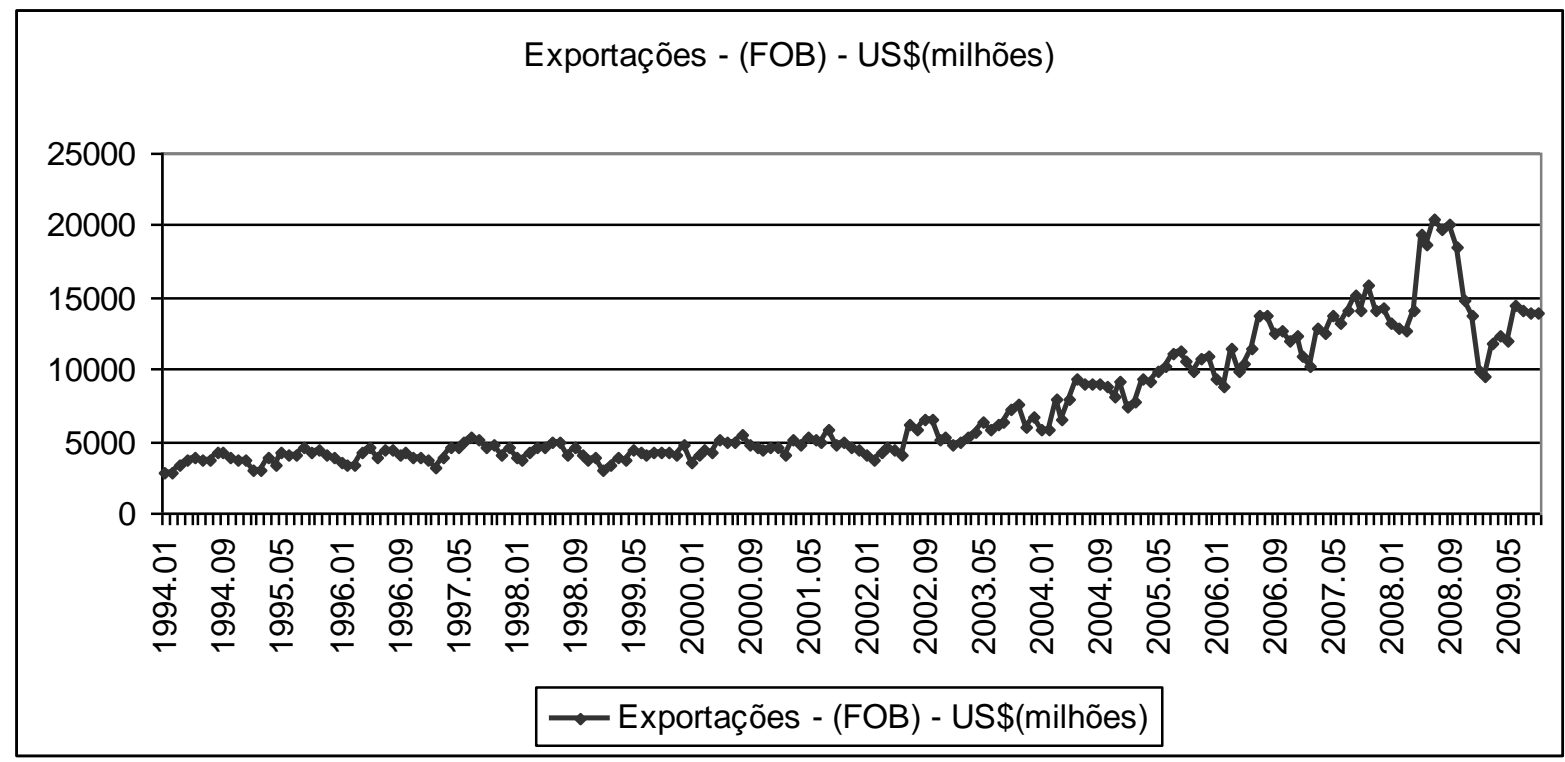

FONTE: MDIC/Secex

A recuperação das exportações a partir de março de 2009 e sua relativa estabilidade após junho do mesmo ano mostram que o pior em relação à queda da demanda externa já passou. 
Outro ponto importante que podemos perceber pelos dados apresentados no gráfico 1 é a relativa estabilidade das exportações de 1994 até meados de 2003 e um grande dinamismo da mesma a partir de então até agosto de 2008. Ou seja, as exportações se mostraram como um elemento relevante na aceleração do crescimento da economia brasileira entre 2004 e 2008 e também na recessão técnica pela qual a economia do país passou no último trimestre de 2008 e primeiro de 2009.

Apesar dessa aceleração das exportações a partir de 2003, a evolução de sua estrutura não tem sido muito benéfica para o seu dinamismo futuro. Como podemos ver pelos gráficos 2 e 3, a evolução das exportações vem ocorrendo com o ganho de participação dos bens básicos na pauta de exportação.

GRÁFICO 2 - EVOLUÇÃO MENSAL DAS EXPORTAÇÕES DE ACORDO COM SETORES E INTENSIDADE DE VALOR AGREGADO COMO PROPORÇÃO DAS EXPORTAÇÕES TOTAIS PARA O PERÍODO 01/1994 - 08/2009

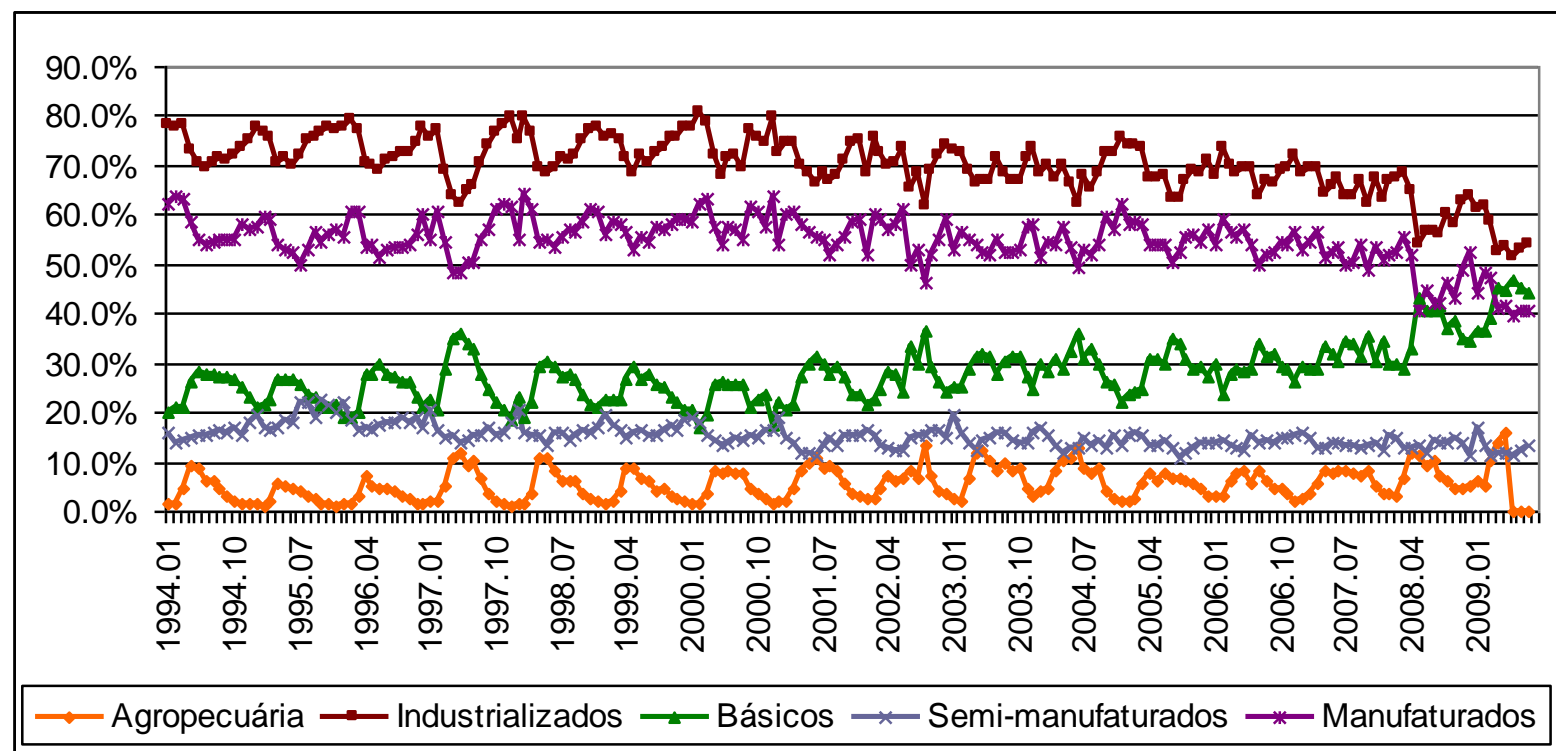

Fonte: MDIC/Secex e Funcex

Pelo gráfico 3, fica ainda mais clara a perda de participação de manufaturados e de produtos industrializados na pauta de exportações. A média móvel dos últimos seis meses aponta uma tendência clara nesse sentido desde o final de 2004 e início de 2005. Mesmo com a recuperação das exportações em 2009, a perda de participação de produtos industrializados na pauta de exportações é alarmante: passou de 60,3\% em Janeiro de 2009 para 53,8\% das exportações totais em agosto de 2009. 
GRÁFICO 3 - EVOLUÇÃO DA MÉDIA MÓVEL DOS ÚLTIMOS SEIS MESES DAS EXPORTAÇÕES DE ACORDO COM SETORES E INTENSIDADE DE VALOR AGREGADO COMO PROPORÇÃO DAS EXPORTAÇÕES TOTAIS PARA O PERÍODO 06/1994 - 08/2009

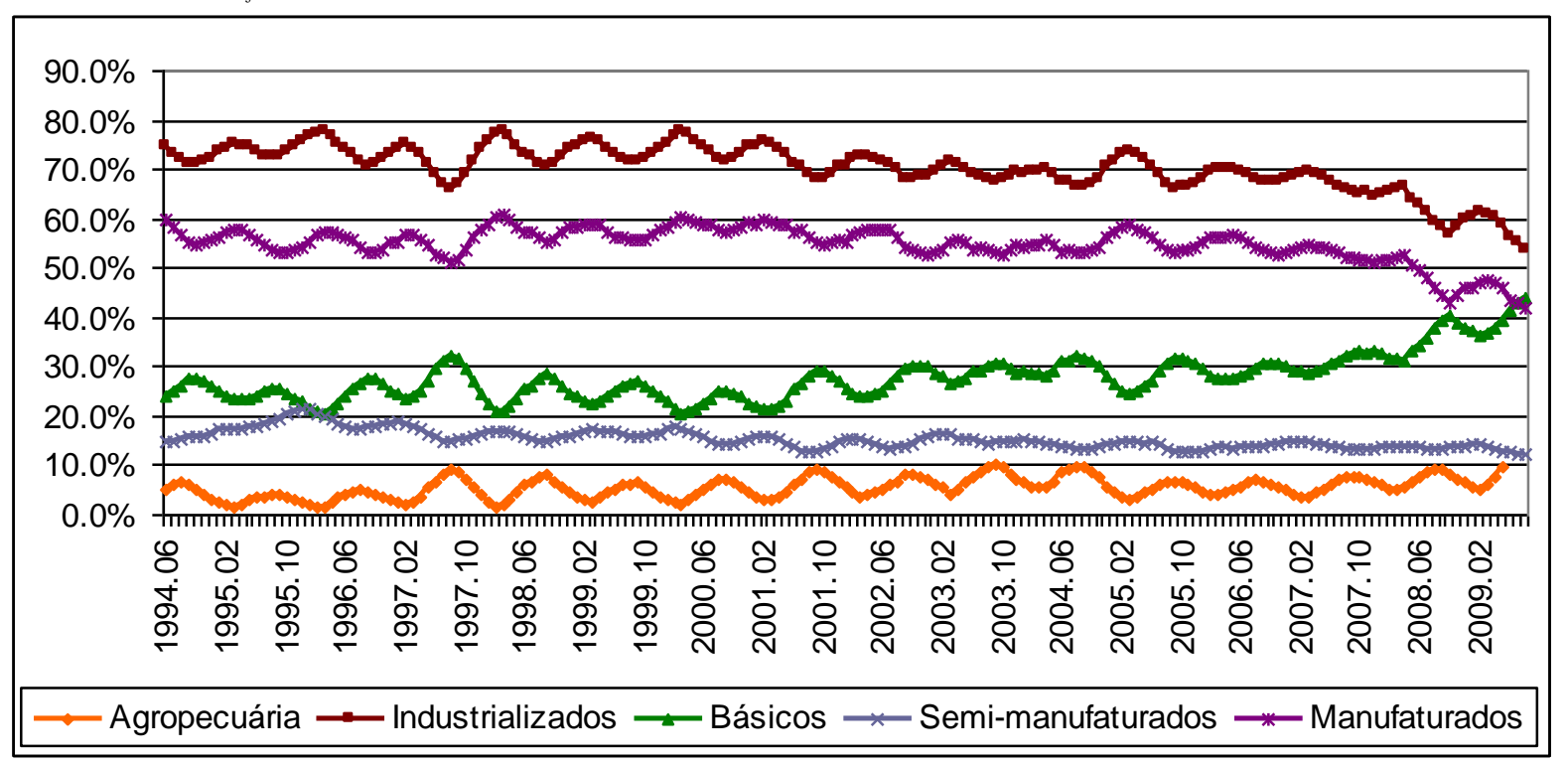

FONTE: MDIC/Secex e Funcex

Em outras palavras, como enfatizado por NAKABASHI, CRUZ E SCATOLIN (2008), o desempenho do setor exportador tem um impacto direto sobre a estrutura produtiva de um país na medida em que determina os setores mais competitivos da mesma e, portanto, com maiores potenciais de crescimento. $\mathrm{Na}$ medida em que a estrutura produtiva de uma economia é importante na determinação do seu dinamismo, esse fator passa a ser crucial no crescimento econômico de longo prazo.

Os autores ainda chegaram a resultados que dão suporte a essa preocupação, ou seja, mostram que o país está ficando mais dependente das exportações de bens baseados em recursos naturais devido ao crescimento da demanda mundial pelos mesmos. Como tais produtos não são dinâmicos do ponto de vista tecnológico e da elasticidade renda da demanda, tal mudança estrutural trará mudanças no dinamismo das exportações brasileiras com consequências negativas sobre seu crescimento econômico futuro.

Outro fator muito enfatizado, o do crédito, não se mostrou como um problema sério devido à intervenção do governo federal e às boas condições do sistema financeiro nacional. Como podemos ver pelos dados apresentados no gráfico 4 , as operações de crédito aos setores público e privado como proporção do PIB não se reduziram com a crise financeira internacional. De fato, o que vem ocorrendo é uma elevação dessas operações como proporção do PIB desde o início de 2003 de forma quase ininterrupta.

É verdade que ocorreu uma queda considerável do financiamento externo no último trimestre de 2008, mas os maiores efeitos foram sentidos pelo setor exportador. Este foi 
afetado duplamente pela queda do financiamento aos compradores dos produtos brasileiros e a queda da demanda externa devido aos efeitos da crise ao redor do mundo.

Outro fator relevante foi a apreensão dos indivíduos em relação ao agravamento dos efeitos da crise no Brasil e a consequente redução do consumo e investimento. Essa mudança no humor dos agentes econômicos foi amena se levarmos em conta a proporção da crise em vários países, principalmente nos desenvolvidos. No entanto, as mudanças de humor aliadas à redução das exportações tiveram impactos inesperados na produção nacional, principalmente da indústria, e que não foram previstos por, praticamente, nenhum analista econômico.

GRÁFICO 4 - DADOS MENSAIS DE OPERACÕES DE CRÉDITO AOS SETORES PÚBLICO E PRIVADO COMO PROPORÇÃO DO PIB: 06/2000 - 08/2009

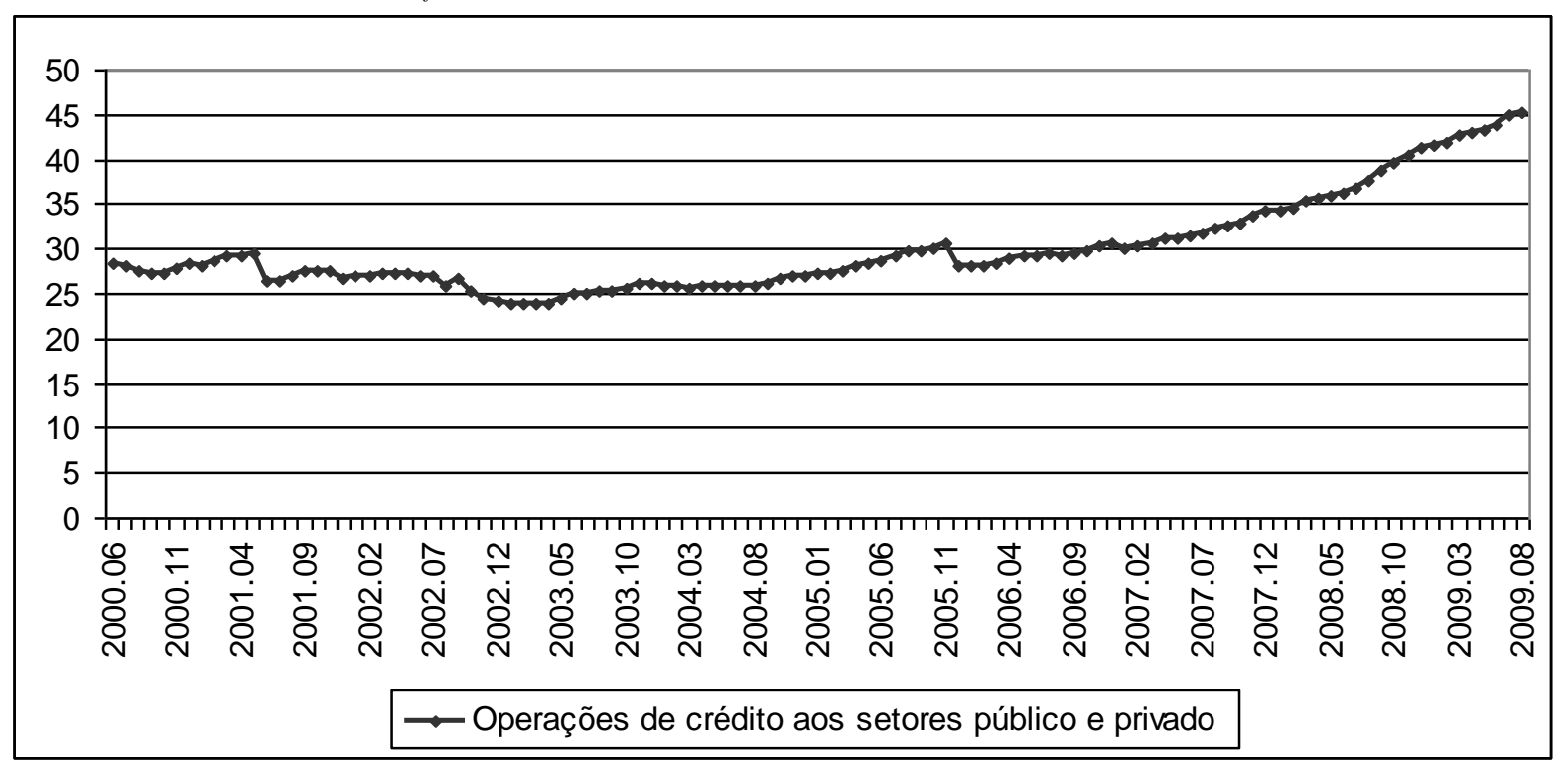

FONTE: MDIC/Secex e Funcex

Como podemos ver nos gráficos 5 e 6 , ocorreram quedas consideráveis na confiança do consumidor e do produtor industrial no último trimestre de 2008 e primeiro trimestre de 2009, sendo que a principal queda ficou por conta dos produtores industriais, com efeitos consideráveis sobre os investimentos do período. 
GRÁFICO 5 - ÍNDICE DE CONFIANÇA DO CONSUMIDOR (ICC): 01/2000 - 09/2009

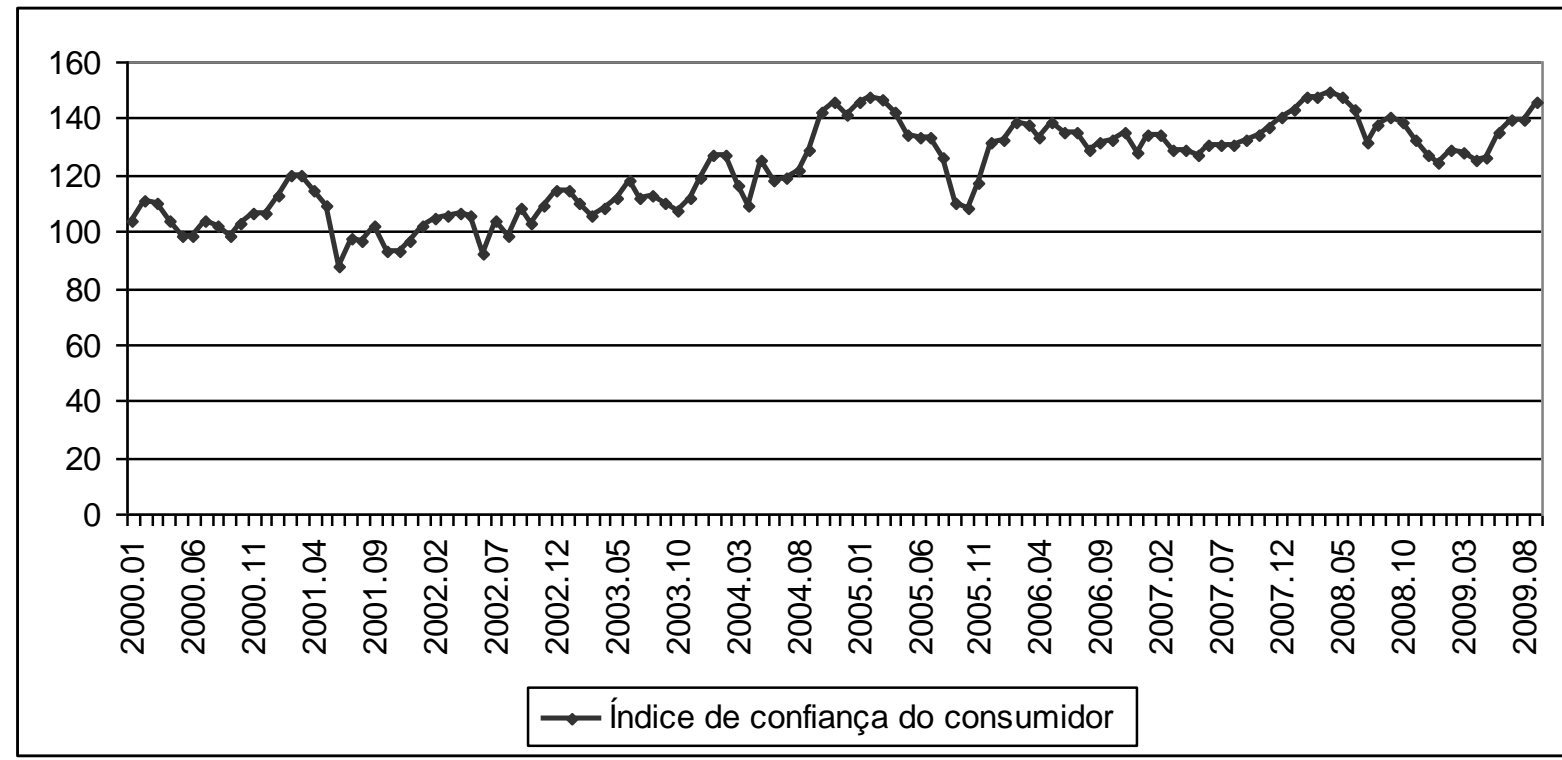

FONTE: - Fecomércio SP

De qualquer forma, a recuperação brasileira foi rápida devido aos fatores apontados anteriormente e as revisões das previsões se mostraram bastante acuradas. Ou seja, a economia brasileira vem se recuperando mais rapidamente do que a maioria das demais economias e os efeitos da crise foram amenos quando comparamos com outros países. Podemos esperar para 2009 um crescimento ligeiramente negativo, como já tinha sido enfatizado, meses atrás, por muitos analistas.

GRÁFICO 6 - ÍNDICE DE CONFIANÇA DO EMPRESÁRIO INDUSTRIAL: 2000 T1 - 2009 T2

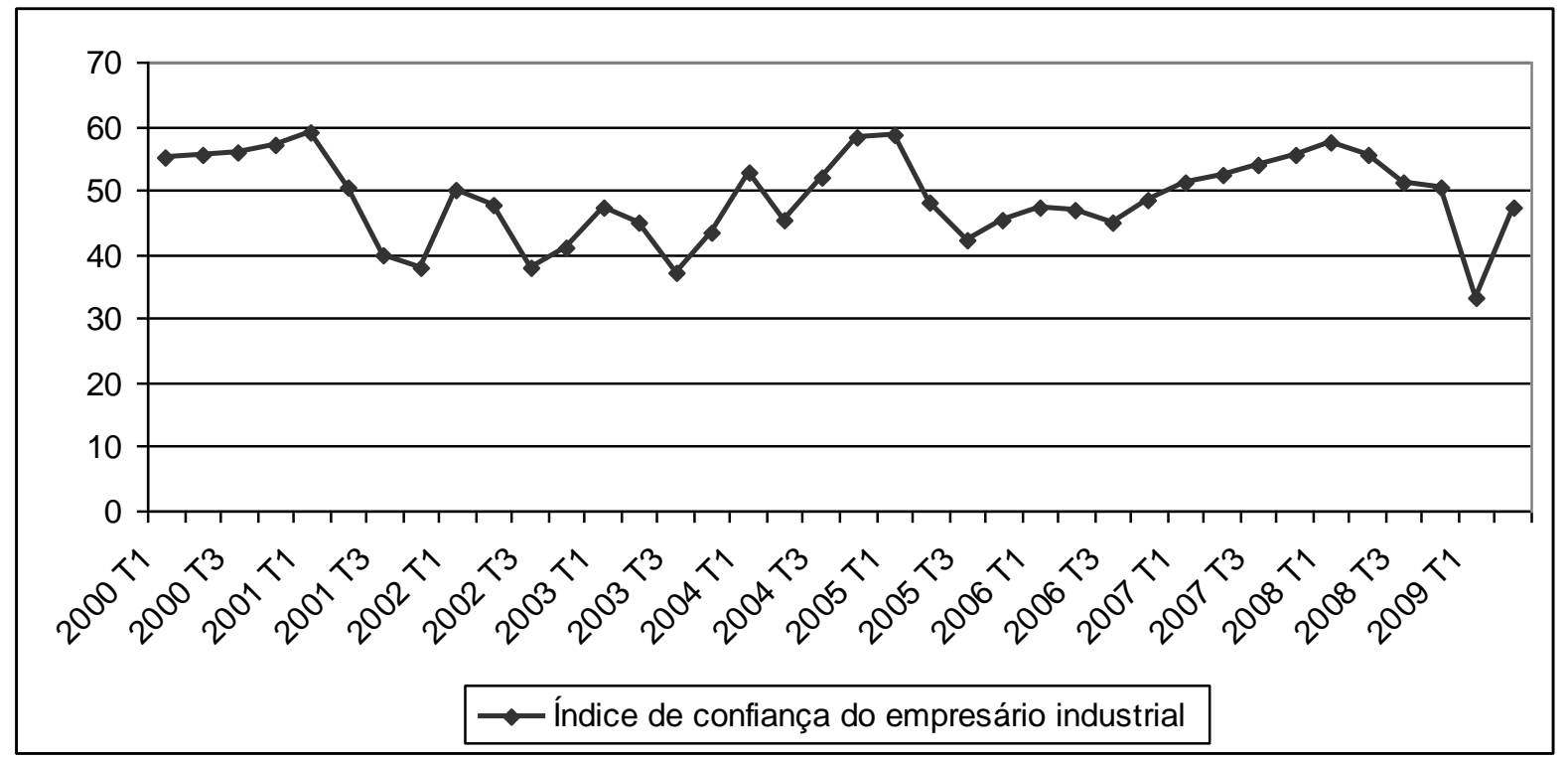

FONTE: CNI 


\section{CONCLUSÕES}

Assim como a gripe suína, a crise causou um certo pânico inicial, mas foi bem mais amena no Brasil em relação aos países do norte, e está se dissipando rapidamente com o início da primavera. A expectativa é que a economia brasileira já apresente uma boa recuperação a partir de 2010. Já no caso da gripe, a incerteza para o próximo ano é maior e depende, entre outras coisas, dos avanços da ciência. No entanto, apesar da recuperação, cabe aos gestores de política econômica uma atenção maior em relação à evolução da estrutura da pauta de exportações.

\section{REFERÊNCIAS}

NAKABASHI, L.; CRUZ, M.J.V.; SCATOLIN, F.D. Efeitos do câmbio e juros sobre as exportações da indústria brasileira. Revista de Economia Contemporânea, v. 12, p. 433461, 2008. 
